\title{
SERVICE ENCOUNTER MISMATCHES: \\ A CONCEPTUAL FRAMEWORK INTEGRATING \\ IT AND JOB DESIGN
}

\author{
George Mechling \\ Beverly Little \\ Western Carolina University \\ Cullowhee, NC
}

\begin{abstract}
As the services sector becomes a larger component of our national economy, it becomes increasingly critical that the management of service operations is addressed systematically. One concern is the interaction of service employees and the technology making up the job design. Effectively matching job design and technology leads to effective service encounters, while mismatches cause shortrun or long run problems for the organization.

Organizational mismatches between job design and supporting infrastructure, specifically the information technology (IT) selected, can give rise to the use and exercise of judgment and discretion by service encounter employees that from the viewpoint of the organization or the customer is extraordinary conflicted, or perverse. Perverse judgments debilitate the organization and degrade the quality of the service encounter. Conflicted and extraordinary judgments ultimately debilitate the organization and may degrade the quality of the service encounter if some customers should perceive others as having received preferential treatment. This paper explores dynamics in managing operations, technology, and human resources that give rise to the exercise of such judgments with the intent to construct a conceptual framework that will explain such judgments and the behaviors that issue from them.
\end{abstract}

\section{Introduction}

The importance of the service encounter to a service organization is well documented in the operations management and marketing literature. This encounter is often the only point of contact the customer has with the organization. It is the context in which the organization provides the customer with what is presumably of value. The customer assesses the value of what the service organization provides on the basis of how adequately it provides explicit and implicit benefits that meet customer needs and expectations. It is thus incumbent upon a service organization to insure that its customer contact personnel are sufficiently supported through appropriate job design, training, and supporting infrastructure that can include an appropriate information technology (IT). This better insures that the organization's customer contact personnel represent it in the best possible way to its customers. 
Job design defines the extent to which customer contact personnel must exercise judgment in meeting customer needs. Ideally, the organization's infrastructure is sufficient to support the conformance of job design to customer needs. This paper will explore dynamics in managing operations, technology, and human resources that give rise to the exercise of problematic judgments with the intent to construct a conceptual framework that will explain such judgments and the behaviors that issue from them. The authors have identified three types of problematic judgments that they label perverse, conflicted, and extraordinary judgments. Perverse judgments debilitate the organization and degrade the quality of the service encounter. Conflicted and extraordinary judgments ultimately debilitate the organization and may degrade the quality of the service encounter if some customers should perceive others as having received preferential treatment. A conceptual framework that provides an adequate understanding of the dynamics that prompt such judgments being made permits more effective planning of the service encounter, the discovery and analysis of the nature of service quality gaps, and suggests actions that can be taken to close those gaps. In cases where these judgments occur, remedial actions can be taken that have both operational and strategic implications. Such a framework can benefit both the organization and the customers it serves.

This paper is divided into five parts. Part One is a literature review. This review provides the motivation for critiquing the quality of service encounters as a technology management and subsequent organizational design issue. This part will touch on the increasingly important role of services in societal economies, the focus on the training of customer contact personnel at the expense of attending to the organizational infrastructure that supports those encounters, and how the introduction of IT into a service organization impacts its infrastructure. Part Two outlines the relationship between business strategy and service package design. Part Three examines the interaction of customer contact personnel's job designs as a function of the design of the service package and the manner in which the service organization employs IT. Part Four, using several cases, introduces an incipient typology of service organization mismatches based on the dynamic factors introduced in the previous parts. Part Five analyzes the cases provided in Part Four for the purpose of suggesting remedies to the problematic judgements those cases depicted. Thus, Part Five demonstrates the usefulness of the incipient typology developed in Part Four as an analytic tool for systemically examining and defining service encounter problems in an environment impacted by the installation of IT.

\section{The Role of Services in the Economy}

The evolutionary course societal economies appear to follow involves a movement toward increasing organizational complexity. Technological innovations result in increased productivity and diversity in the extractive (including agriculture) and manufacturing sectors of an economy which result in shifts of 
the labor force into other sectors. ${ }^{1}$ This shift is made possible only because of a simultaneous accompanying increase and expanding diversity of business, trade, infrastructure, social/personal, and public administration services. Without the direct and indirect linkages that exist between the material goods producing sectors and these service sub-sectors, increased productivity and diversity in the goods producing sectors would not be viable (Reddle, 1986). Adequately performing this increasingly complex function has resulted in the percentage of the U.S. workforce allocated to services steadily increasing at a modest exponential rate in this century. Since the 1960's, services have accounted for more than half of that labor force with no indication that the continued growth in this proportion has passed an inflection point (Fitzsimmons \& Fitzsimmons, 1997). By 1995, service industries accounted for $75 \%$ of GDP and $78 \%$ of employment (Keltnwer \& Finegold, 1999). Therefore, it becomes increasingly important that services be the focus of critical attention for the purpose of evaluating their functional effectiveness and efficiency. If not done, our understanding of services for this time and the future may prove inadequate. Eventually, this inadequacy will lead to their practical mismanagement and the degradation of the effectiveness and efficiency required of services to contribute toward the realization of healthy activity of an evolving economy.

\section{Focus on the Service Encounter}

Addressing the concerns for service quality and effectiveness has been done in several different ways. The most basic way is to analyze the service encounter, the interaction between the customer and the service delivery or customer contact personnel. Research on service encounters may focus on perceptions of the persons involved in the exchange. Hartline and Ferrell (1996) devised a model that addressed the management of service encounter employees based on the perceptions of the three groups that had previously been studied separately; managers, employees and customers. Their literature review and the literature search this paper's authors conducted inductively suggest that the preponderance of studies exploring service quality and effectiveness have limited themselves to issues related to micromanaging service encounters.

\section{Global Views of Service Quality and Effectiveness Management}

In addition to service encounter models, more global views of the management of service performance have been addressed. Bowen and Lawler (1992) stress that decisions concerning how to manage service employees should be based on five contingency factors. They state that an organization should consider its basic business strategy (high volume versus customized output), the nature of the relationship to the customer (transactional versus relational), technology (routine versus nonroutine), business environment (predictable versus turbulent), and types 
of managers and employees (Theory $\mathrm{X}$ versus Theory $\mathrm{Y}$ ). Thus, management of services is based on a set of variables that constitute settings in which service encounter perceptions are formed.

Singh and Deshmukh (1999) advocate the application of Total Quality Management (TQM) principles to the management of services. They stress that TQM is a systems approach to organizations in which every element interacts with every other element. Like Bowen and Lawler, they argue that service quality is not simply a function of what the manager wants the employee to do, or what the customer perceives, or how well trained the employee is. The success of a service organization is predicated more on the interaction of many its aspects. One systems approach to achieving service quality and effectiveness is found in Hauser's and Clausing's (1988) "house of quality." Applying the "house of quality" to the service encounter, Fitzsimmons and Fitzsimmons (1997) show how marketing, design, engineering and manufacturing (delivery) must be coordinated in order to actually meet the customer's desires.

\section{Information Technology (IT) and Global Views of Service Quality and Effectiveness}

A global or systemic view is critical in managing an organization's adoption of a technology, particularly when that adoption directly involves the organization's operations. The manufacturing management literature of the 1980's and early 1990 's, for example, is replete with discussions that advocate this perspective. This is so because its contributors found that the repercussions of introducing a new technology into a manufacturing concern ran through virtually every aspect of that concern's organizational structure. They further found that unless that concern accommodated the adoption of its new technology by reorganizing itself so as to effectively exploit its new technology's capabilities, the end result was far more likely to be counterproductive and deleterious than beneficial (Festa, 1987; Gerwin \& Kolodny, 1992; Meredith, 1986).

Both Sciulli (1986) and Rodger and Paper (1998) argue that what has been said about manufacturing organizations and their adoption of new technologies holds true for service organizations as well, and their adoption of IT, in particular in both the banking and healthcare industries. Their argument is in part supported by the work of a committee of the National Academy of Sciences that identified a phenomenon that it labeled the "information technology paradox." This paradox refers to the lagging growth in service sector productivity when compared to the growth in investments in service sector IT. The committee provided a list of several explanations for this paradox. At the top of its list was the mismanaged employment of information technology (Heitoff, 1998).

This paper pursues research of the sort anticipated in the efforts of those cited in the previous paragraph. It does not however, discount the importance of the service encounter, that is, the interaction between customers and customer contact 
personnel. Rather, it regards successful service encounters as resulting from a coordinated convergence of organizational factors; customer contact personnel training, job design, the reward/punishment system, empowerment, and the manner in which IT is integrated with the rest of these factors forming an organizational infrastructure supporting those encounters. By rigorously analyzing service operations and the encounters they produce as a function of the effectiveness with which technology and its adoption are managed, it may be possible to discover a basis for identifying types of service failures resulting from infrastructure design flaws integrating IT.

\section{Business Strategy}

Organizational strategy begins with the organization's mission statement that identifies what service the organization provides. This implies an interaction between the target market segment and the service provided and an interaction between technology and personnel employed to produce and deliver the service and how the service package is designed (Figure 1).

Figure 1

\section{Service Package/Job Design and Market Interaction}

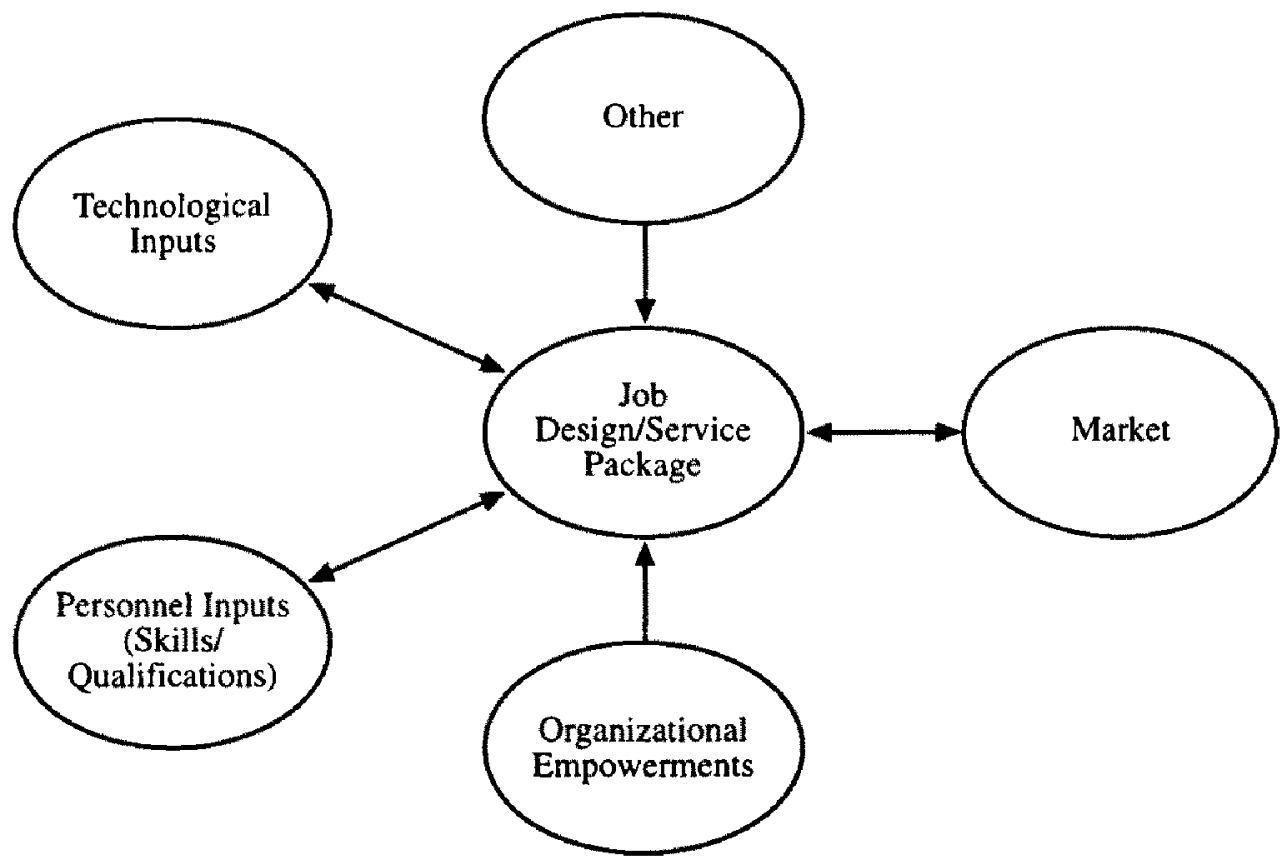

Figure 1 illustrates an interaction between the Job Design/Service Package and its market via the service encounter. The design of a job consists of what customer encounter personnel are expected to do based upon their skills and qualifications and organizational constraints (tempowerment and other inputs). These expectations 
cannot, however, be divorced from the technology through which customer encounter personnel act. A service is produced as a response to an existing market that it can opportunistically enter, as an instrument that calls new kinds of markets into being, or as a combination of both. The Internet auction company, eBay, is a recent example of such a combination. On-line auctioning existed prior to eBay's appearance. However, eBay took on-line auctioning several steps beyond what already existed to an interactive environment and redefined customer expectations. As a result, eBay has virtually monopolized the on-line auctions industry and has dramatically expanded the industry's market in which it is the dominant player, attracting new customers while holding its old ones (Dunkin, 1999).

The nature of services is such that their production and consumption is simultaneous (Mills \& Moberg, 1982; Schmenner, 1986). Consequently, the production and delivery of a service constitute its encounter with the customer whose expectations are standards against which the efficacy of the service is evaluated. How the production and delivery of the service are designed into the service package is therefore, critical. The technology selected for the service package plays a part in that design (Fitzsimmons, 1983). On the one hand, the service package is first designed to which a suitable and available technology is then attached. Such is the case, for example, with fast foods where IT systems are employed to open transactions and communicate customer orders to the back room. IT may be employed in the back room to monitor operations and bring the transactions to a close (Mechling \& Little, 1997). On the other hand, technology may restrict how decision makers would like to design their service packages or it can open up the design of a package so as to include heretofore infeasible possibilities by which competitive advantages can be pursued. Such is the case, for example, in teleradiology (Dwyer, Sayer, \& Honeyman, 1992; Franken, 1998). Recent developments in IT (particularly compression and transmission technology) and standardization in the way imaging equipment generates its images has made it technologically possible to physically decouple radiologists from the images they must read. As a result, access to radiological services has become decidedly more timely and widespread for potential customers (especially those in remote locales) than heretofore thought possible. Such developments have created opportunities to redesign the initial service package and revise customer expectations by reinforcing initial diagnoses with second and third opinions and exploiting subspecialization skills while at the same time, reducing the turn-around time to patient (customer) consultation (Heitoff, 1998).

\section{Service Package Design}

The widely accepted means of categorizing service organizations is through the use of typologies (Cook, Gho, \& Chung, 1988; Kellogg \& Nie, 1995). One of the most widely used typologies is Lovelock's (1983) that strategically profiles a service package. Of particular interest to the authors of this study is Lovelock's typology that juxtaposes \pm customization of services with \pm exercise of judgement 
and discretion by customer contact personnel in meeting individual customer needs. ${ }^{2} \mathrm{~A}$ barber, for example, is expected to provide the customer more customized services than a home pest exterminator who has a finite set of program modules from which to select and much less judgment to exercise. Like the barber, an attorney also performs a customized service but the attorney must use and exercise judgement and discretion that exceeds the judgment and discretion a barber uses and exercises and certainly exceeds the judgment and discretion the home pest exterminator must use and exercise (Figure 2).

It is expected that similar services will position themselves similarly in Lovelock's typologies. Technological innovations in service production and delivery can, however, lead to typological repositionings of a service operation and a consequent revision and redesign of its profile and service package. One must assume that such redesign of the service package is done to derive some competitive advantage or at least prevent the service operation from being competitively disadvantaged. The various technologies an organization chooses to employ therefore interact with all the typologies that strategically profile it and contribute to the design of the organization's service package. The specific interaction between the employment of IT and the extent to which customer contact personnel are empowered or not empowered to use and exercise judgment and discretion to meet customer needs during the service encounter is this study's object of analysis. Working down the main diagonal of Lovelock's typology of customization and discretion, the more standardized the service, the less use and exercise of judgement and discretion by customer contact personnel is necessary. The more customized the service, the more use and exercise of judgement and discretion by customer contact personnel is necessary. ${ }^{3}$

Figure 2

\section{Lovelock's Typology}

Increasing Standardization

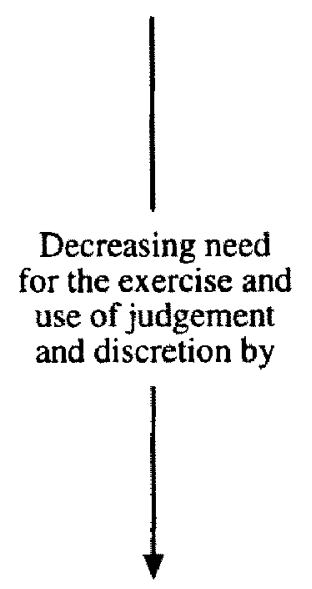

\begin{tabular}{|c|c|}
\hline $\begin{array}{c}\text { Professional Services } \\
\text { Surgery } \\
\text { Taxi Service } \\
\text { Beautician } \\
\text { Plumber }\end{array}$ & $\begin{array}{c}\text { Mass Education } \\
\text { Preventative Health } \\
\text { Programs } \\
\text { College Food Service }\end{array}$ \\
\hline $\begin{array}{c}\text { Telephone Service } \\
\text { Hotel Services } \\
\text { Most Retail Banking } \\
\text { Family Restaurant }\end{array}$ & $\begin{array}{c}\text { Public Transportation } \\
\text { Routine Appliance Repair } \\
\text { Movie Theatre } \\
\text { Spectator Sports }\end{array}$ \\
\hline
\end{tabular}


In most cases customer contact personnel are the sole points of contact customers have with an organization providing them the service they seek. Their evaluations of it and decisions about future patronization of it are largely determined by how customer contact personnel manage to present the organization during service encounters. Thus, how the judgment and discretion customer contact personnel are empowered or not empowered to use and exercise and the IT they employ interact in the design of the service encounter can be decisive if the organization is to attract and hold its customers.

The extent of judgment and discretion customer contact personnel are expected to use and exercise understandably varies from service to service. However, what about situations that do not precisely conform to a given service for which the technology has been designed? Judgment and discretion used and exercised by customer contact personnel in such situations is important for at least two reasons. First, decisions including judgment and discretion or the lack of them may affirm or contradict organizational objective or policies. Furthermore, unacceptable decisions issuing therefrom will result in positive or negative encounters from the customer's viewpoint. These decisions may be particularly important in achieving a service recovery when a service failure has occurred or is imminent.

\section{Choice of IT}

A service operation employs IT in order to increase and improve service efficiency and effectiveness in a way that is consistent with its competitive strategy. Fitzsimmons (1993) suggests that IT accomplishes this by creating another entry barrier, generating revenue, creating a database upon which empirically based decisions can be made, and enhancing productivity. Customer contact personnel draw on and contribute to such a resource when they access IT to support their service encounter activity. Their access to the IT system can, however, vary. They may be restricted with respect to the range of information they can browse. They may also be restricted with the respect to the range of information they can input. Fast food customer contact personnel can browse virtually no range of information and the range of information they input into the system is restricted to the orders they take. Their job can be characterized as being almost completely circumscribed by the technology associated with their job. ${ }^{4} \mathrm{~A}$ customer wants, for example, a taco with allowable modifications. A predetermined closed set of intermediate steps is synchronic with the outcome. The employee merely selects predetermined and technologically constrained choices, as one would push a stop or start button on a machine.

Airline ticket counter personnel must, on the other hand, be able to browse routings, schedules, and ticket information for the entire industry in order to input the orders they take. The outcome of the order (a customer being at point $B$ after having been at point $A$ ) is something separate from the subset of intermediate steps that achieve it (getting to point B from point A). Airline ticket counter personnel must create that subset (construct a routing). They use IT to expedite 
the construction and creation of that subset. The IT they employ does not therefore, so nearly circumscribe their jobs as with the fast food order taker.

Figure 3

\section{Lovelock's Typology}
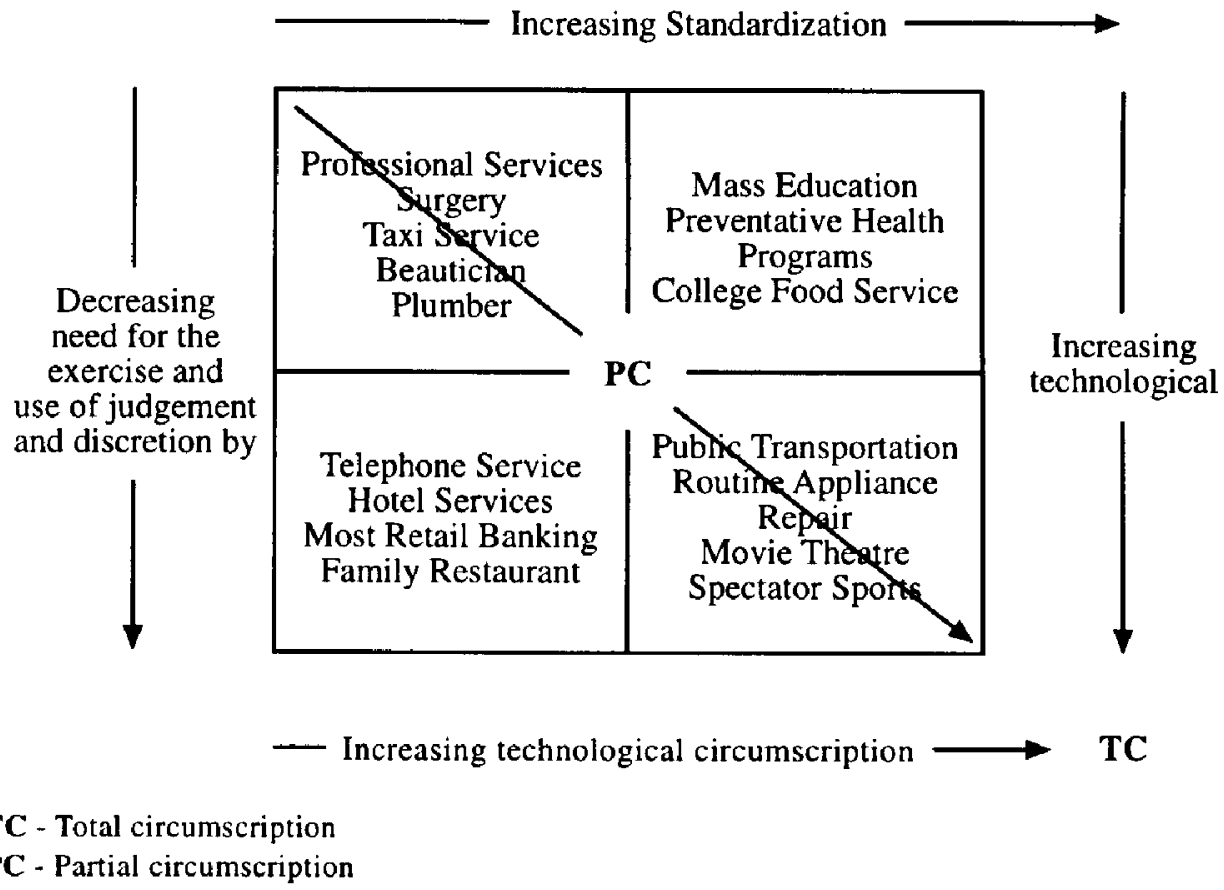

\section{Job Design}

Job design for service employees has been categorized as a "production line" approach or an "empowerment" approach (Bowen \& Lawler, 1992). The production line approach, as its name implies, is based on a Tayloristic view. It is based on four tenets - simple tasks, clear division of labor, substitution of equipment and systems for employees, and little decision-making discretion of employees. This design seeks to gain customer satisfaction through efficiency, consistency, and low costs.

The empowerment approach, on the other hand, allows employees to make decisions that in the production orientation would be reserved for higher-level management. In such settings, jobs are less simple and more broadly defined and employees are given more latitude. In order for employees in such a design to be effective, they must have access to needed information, knowledge about how to use the information, and sufficient power to meet customer requests during the service encounter.

The production line approach gains its low costs through consistency, which can be translated into lack of personal service. This means that as the service 
encounter is standardized, the choice of actions possible by the service provider is limited. Attempts to provide personalized service in such a setting would drive up costs and violate the competitive advantage of the firm. In addition, while the customer receiving the personal service may be more satisfied, other customers who are receiving slower service because of it may be disgruntled.

The empowerment design is slower, less efficient and more expensive to operate. It requires careful selection and extensive training of employees. This design could put a firm at a competitive disadvantage from a cost standpoint servicing encounters of a routine form.

Companies must clearly define their business strategy and know the environment and the customer base they pursue in making a decision concerning job design for their employees.

\section{Interaction of Job Design and Information Technology}

It is imperative with the production line job design that IT is installed as a part of that design so as to facilitate matching it to the service encounters anticipated. The number and nature of the options from which the employee chooses should then be limited to matching the constraints on their decisionmaking authority. Any access to additional information would not only be of no use; it would actually deter efficiency. For example, if all hamburgers are prepared to the same degree of doneness, giving a customer encounter person the option of asking a customer how he/she would like the meat cooked would slow down the process. In fast food, cash registers (which also communicate orders to the backroom) prompt order-takers through the decisions that are allowable. Thus, the more standardized the service the more easily circumscribed technologically it can be $\mathrm{e}^{5}$ because the reality of the encounter is simple and presumed to be more easily captured than encounters in which provided services are customized and the outcome of any one such encounter is variable. The more circumscribed technologically the service is, the more efficiently the service can be performed but the more dependent upon the circumseribing technology customer encounter service personnel become.

In the case of the empowerment job design, use of judgment and exercise of discretion on the part of employees demands access to information. If the employee is to provide personalized service, the IT system must provide access to information concerning options and their availability. Thus, if the service can be customized and the service provider has discretion, the information must be provided to enable that discretion to be used. This means that the less standardized the service the less easily circumscribed technologically it can be because the reality of the encounter is too complex and varied in individual outcomes to be easily captured, this does not mean however, that these customer contact personnel are any less dependent upon the technology that less extensively circumscribes their job than their counterparts who provide standardized services. Rather, their dependence is 
different. They cannot effectively use and exercise judgment and discretion that, by definition, are parts of their job without IT.

\section{A Typology of Service Organizational Mismatches}

One may assume that for any given range of actions provided to customer contact personnel, protocols exist that prohibit, obligate, and permit selections of alternatives that depend on the encounter circumstances. Within this normative framework, the exercise and use of judgment and discretion can be extensive or limited to the point of being virtually nonexistent. Where their use and exercise are extensive, it is to presumably match and conform the job to the needs and expectations of specific customers. Where their use and exercise are virtually nonexistent, the job as it is designed and its supporting organizational infrastructure are presumably adequate to also match and conform the job to the needs and expectations of specific customers. Organizational mismatches, therefore, arise between the job design and its supporting organizational infrastructure when customer contact personnel are confronted with a service demand that cannot be met without their being at odds with how they are to do their job and/or with the goals and objectives of the organization. This section provides a typology of such mismatches based on job design and IT as the significant infrastructural component of interest providing the contexts in which judgement and discretion are used and exercised.

Violations of the job design can occur in a number of ways. First of all, do customer contact personnel follow courses of action that fall outside what the technology circumscribes for them? Examples of such behavior are abundant. One can imagine an employee breaking open a cash register to make change for a customer because there is no sale with which to ring it open or no access to a key with which to unlock it. One can also imagine a situation where a hotel guest is permitted to take a free muffin from the breakfast line because the cash register is not programmed with a "muffin" key. As job violations go, breaking open a cash register to make change is certainly more extreme than giving away muffins. Both cases, however, suggest that the customer contact job as it is technologically circumscribed may be inadequately designed to satisfactorily address every encounter for providing service that might come its way.

Such design inadequacies typify mismatches. Such mismatches could lead to service failures that in some cases only the extraordinary use and exercise of judgment and discretion can repair. Thus, the exercise of extraordinary judgment is a legitimate topic to examine.

Figure 4 illustrates the process by which the use and exercise of extraordinary judgement and discretion occurs. The job design/service package is totally circumscribed, consisting of other organizational inputs including customer encounter personnel who have no leeway whatsoever using or exercising judgement and discretion in their conduct of the service encounter. As long as these encounters are routine, i.e., match the job's design, encounters are successful 
and customers are satisfied. Non-routine encounters, on the other hand, do not match the job design. From the viewpoint of the organization, such an encounter is a non-event. It is certainly not a success but neither is it a failure, for the organization has not defined the customer's need as something the job was designed to satisfy. From the viewpoint of the customer seeking satisfaction, however, it is hard to argue that the encounter can be anything but a failure. The customer encounter personnel may, however, be able to satisfy a non-routine need and achieve a service encounter success attended by a mix of other results, but they must do so by abandoning altogether the use of the technology that is a fundamental functional part of their job's design.

\section{Figure 4 \\ Extraordinary Judgements/Discretion}

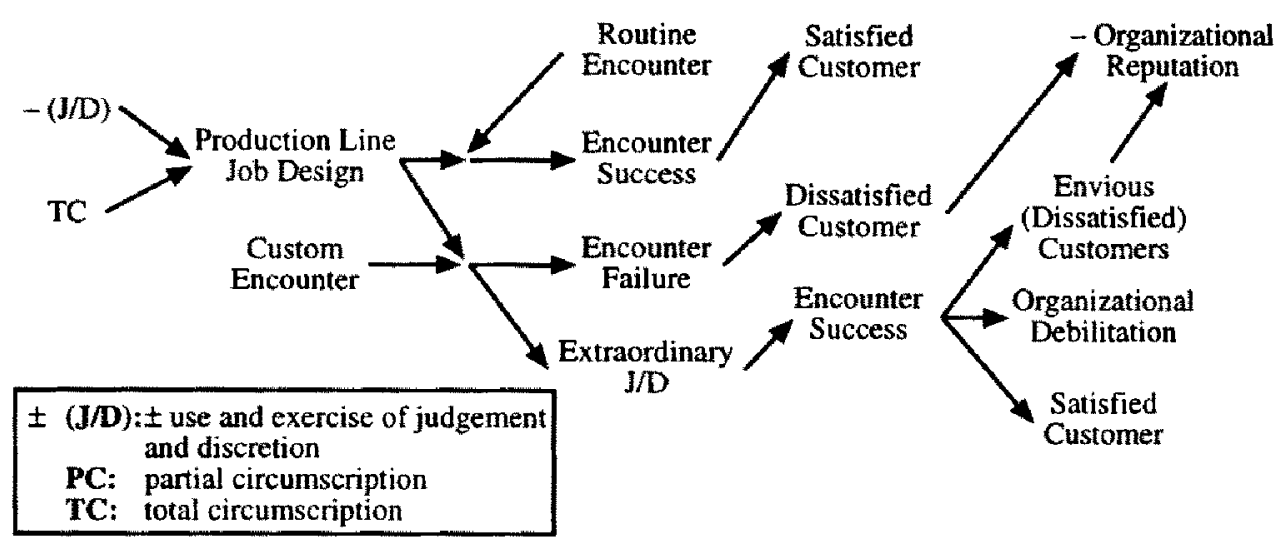

Violations can occur within the job as designed and technologically circumscribed. These violations involve judgments that disregard organizational protocols and lead to particular technologically-doable ends that the technology installed is not intended to support. Such judgments may be conflicted or perverse. The exercise of judgments that are conflicted may result in a service encounter success in the view of the customer and probably the customer encounter service person as well. Take for example, a customer who wishes to make a last minute change to his/her discount fare airline ticket at an airport airline ticket-counter. Penalties for making such changes are part of the terms to which the customer agrees when he/she purchases such a ticket. Yet, the customer encounter service personnel at airline counters in airports rarely assess such penalties. Not only will they change flights for discounted tickets, they will even change airlines. They are perfectly capable of assessing such penalties, taking money, even making change. They have the IT available to do it, but they rarely do despite the fact that airline management directs them to the contrary. Apparently, such personnel are empowered to exercise a great deal of individual judgment and discretion in such matters as they weigh such issues as customer flow, acceptable aircraft load factors, 
and customer goodwill. ${ }^{6}$ The authors regard conflicted judgments as being made in situations where the customers can be better served even though providing such service could prove detrimental to the service organization.

Figure 5 illustrates the process by which the use and exercise of conflicted judgment and discretion occurs. The job design/service package consists of a partially circumscribing IT and other organizational inputs including customer encounter personnel who have substantial leeway in terms of the judgement and discretion they can use and exercise in their conduct of the service encounter. Given that non-routine/custop service encounters are within the realm of possibility, success certainly occurs when customer contact personnel use and exercise judgement and discretion only insofar as they choose to strictly adhere to organizational guidelines and policies. Thus an airline customer contact person could change a customer's discount ticket and assess the prescribed penalty and neither party would have any reason to regard such an encounter as anything but successful, for the desired change was made and the customer was assessed only the agreed-upon change fee. Such customer contact personnel can, however, use and exercise their judgement and discretion and not adhere to policies by choosing not to assess a customer a penalty for changing a discount ticket. This also results in a successful service encounter from the point of view of the customer. It is, however, one that is lavish compared to assessing the customer a penalty for making the change. Furthermore, such a choice on the part of the customer contact person does not involve abandoning the technology that is a part of his/her job design but putting it to use.

Figure 5

\section{Conflicted Judgements/Discretion}

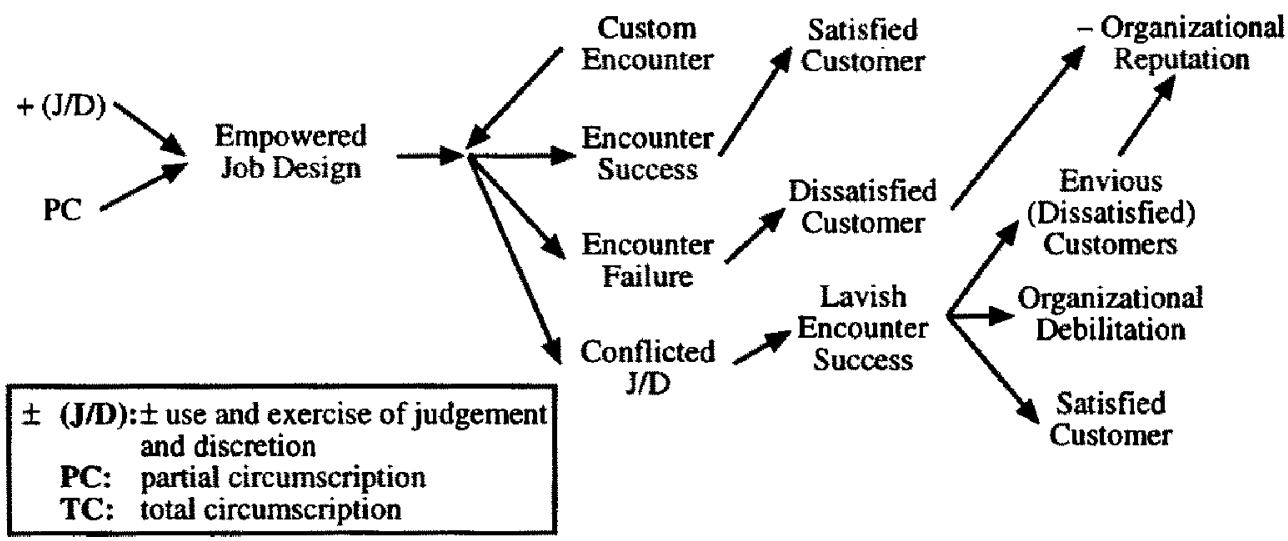

The exercise of perverse judgments and the behaviors that ensue are often motivated by a perceived need on the part of various employees to "beat the system" and almost invariably jeopardize the success of the service encounter and well being of the service organization as well. A study the authors did of a 
well-known fast-food service franchise, referred to as Flex-Mex, serves as an example (Mechling \& Little, 1997). Flex-Mex's market qualifiers were a number of competitive priorities, "mass customization" of its product and speed of service. Its employment of IT contributed to a great extent in making this possible. FlexMex's cash register(s) transmitted orders through a computer to display screens located in its back room where ingredients were assembled into menu items and orders filled. The assembly employee who completes the last step in filling the order removes it from the display screen. The screen then displays the next order in the queue. Screens may hold many orders at a time and rarely do they become overloaded. This is due in part to screen capacity and in part due to the fact that an order can be "bumped" (erased from the screen) at anytime. Assembly personnel, therefore, do not necessarily need to wait until a customer physically receives his/her order to remove that order from the screen.

IT, however, performed more than an order communication function for FlexMex. It was used to monitor order delivery speed performance and foodstuffs wastage. Crews were rewarded for above-standard performance with half-price menu items for their meals and were denied half-price menu items for their meals and/or penalized individually with demotions or dismissal for sub-standard performance. As a result of this additional set of functions IT performed, assembly personnel would often "bump" an order before it was filled because that would stop the timer on that particular order. Thus, assembly personnel were able to insure that no one order ever took an excessive amount of time quite independent of whether a customer had to wait an excessive amount of time for his/her order. Such a practice also resulted in misfilled orders since employees often carried as many as five different orders in their short-term memory. Several other downside phenomena accompanied these service failures. First, the correct order had to be refilled. This took additional time but IT was not timing this activity. Second, the shelf life of these menu items is very short once prepared, less than five minutes in most cases. Thus, a certain amount of foodstuffs had to be scrapped if no new customer came along shortly ordering the same item. The assembly crew could only compensate for this waste by shorting other orders by small amounts of the ingredients.

Figure 6 illustrates the process by which the use and exercise of perverse judgement and discretion occurs. The job design/service package consists of a partially circumscribing IT and other organizational inputs including customer encounter personnel who have no leeway whatsoever in terms of the judgement and discretion they can use or exercise in the conduct of the service encounter. What is noteworthy is that it is not an encounter with a customer that elicits a perverse use of the technology of which the job design is in part constituted, but the encounter with limited measures of employee performance upon which a system of rewards and punishments is based. The encounter with the customer is irrelevant. 
Figure 6

\section{Perverse Judgements/Discretion}

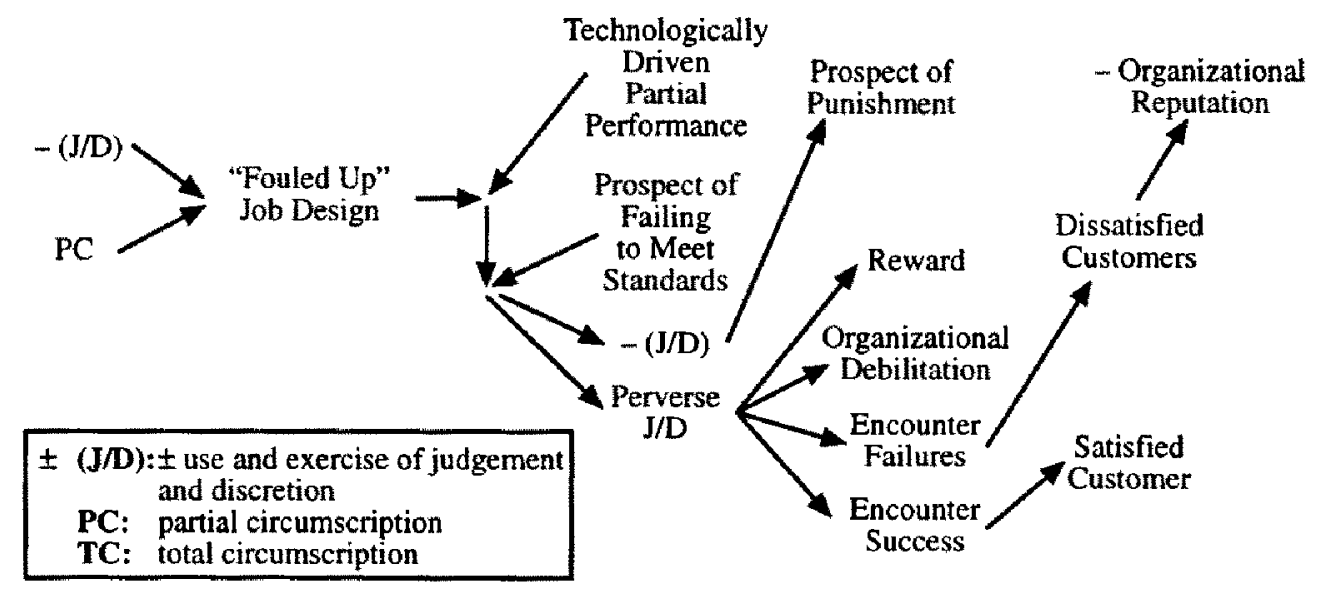

\section{Analysis}

Analysis of these cases can establish the utility of a conceptual framework to explain the use of judgment by customer contact service personnel when acting within the technology paired to their jobs. Thus, what would otherwise be anecdotal information can be processed into knowledge about the management of operations, technology, and human resources. Such knowledge will permit decisions to be made as to the extent to which customer contact service personnel should use judgment and exercise discretion to the benefit of both the customer and the servicing organization.

The first case involves two examples in the use of extraordinary judgment. One is the example of breaking open the cash register to give a customer change. The other is the hostess who gives away breakfast muffins. Both examples suggest that the involved customer contact personnel are committed to effectively serving the customer. Both, however, constitute organizational mismatches that derail the organization's pursuit of its goals. The circumscribing technology has not adequately comprehended all the different kinds of service encounters involving customer needs. Given that service operations management does not recognize needing change or wanting only a muffin as legitimate customer needs, the protocols in place are not adequately conceived. The ends of the organization and the ends of its customer contact personnel are at odds because the technology as employed by the organization is divisive.

Given the conceptual framework the authors have constructed several alternative courses of action that can be proposed. There may be very good reasons why customer contact service personnel are not allowed to make change. If management wishes to continue that restriction, the protocols must be very clear that customer contact service personnel are not so empowered. If the failure to make change 
results in needless loss of goodwill, the most obvious alternative course of action would be to give the operator the cash register access key. Such a change in policy would invariably require additional protocols as to whom change can be given and when it can be given, thus empowering the register operator to use his/her judgment and exercise discretion in applying those protocols.

Concerning the muffin give-away example, the most obvious failure is that the technology inadequately captured the range of service encounters. This failure should be easy to rectify by merely programming the register with alternatives to selling just the buffet. This would further circumscribe the register operator's job and remove the need for extraordinary judgments from time to time. Given that part of the hotel's breakfast line consists so often of a breakfast buffet, there may be little incentive to go to that kind of trouble since little control would be exercised over breakfast buffet customers as to how many muffins they might take in the first place. Be that as it may, over time, the practice of muffin give-away could prove costly and, while the cost of operating a breakfast buffet line is partially subsidized by hotel registrations, there is little reason to carelessly add to its cost.

Despite upper management level directives urging airline ticket counter personnel to assess penalties more frequently, they continue to use and exercise their judgment and discretion in this matter and assess them much less frequently than upper management would prefer. They do this without fear of sanctions. This is a case of conflicted judgments and could of course be resolved by technologically circumscribing the process by which those changes are made. It would be an easy matter to program for such changes so that the change could not be finalized until the penalty was assessed for the change. This would take the control of assessing such penalties out of the hands of the airline ticket counter personnel. Such programming has not however, been done.

The reasons for not doing such programming could be several, the most likely one being that airline ticket counter personnel have as a primary task facilitating the movement of traffic through the terminal. Anything contributing to impeding that movement must be regarded as undesirable and costly. Airline ticket counter personnel are, therefore, left to use judgment and exercise discretion in such matters since assessing penalties could prove time consuming. On the other hand, changing discounted tickets disrupts the yield management schemes designed to optimize flight revenues. Changing discount tickets involves a cost for which airlines can make a compelling argument. Penalties are assessed to offset this loss. This conflict between what is practiced and the protocols in place suggests that from the standpoint of the conceptual framework the airline ticket counter personnel have not been sufficiently empowered. They certainly have been sufficiently empowered in terms of their use and exercise of judgment and discretion. They have not, however, been sufficiently empowered to have a say in how the protocols are devised and applied (Bowen \& Lawler, 1992). The higher levels of airline management would do well to so empower them. Working together on equal footing, both parties might be able to agree on protocols that would garner more 
revenue through penalties that would offset the organization's yield management shortfalls while keeping the traffic moving at an acceptable rate.

The case of Flex-Mex provides a true-life example of the judgments service personnel (in the case, back room personnel) make that are perverse. Unlike extraordinary and conflicted judgments that work for the most part to the benefit of the customer but are potentially debilitating to the service organization, perverse judgments are debilitating to the service organization including the quality of the customer service it provides. The conceptual framework the authors have constructed provides a basis for identifying the factors that contributed to the Flex-Mex mismatch and proposing alternative courses of action to remedy it.

First, the extent to which technology circumscribed the jobs of the Flex-Mex employees, particularly those in the back room, was not extensive enough. This resulted in Flex-Mex's reward/punishment system and its performance measurement method that were intended to motivate high performance actually leading to the contrary (Kerr, 1995). In addition, Flex-Mex's employees were not sufficiently empowered for management to be receptive to their observations concerning their dysfunctional work setting or suggestions they might submit as to how that work setting could be made more functional. Thus alienated, they acted in a way to protect their individual interest that put them at odds with some of the organization's goals and objectives.

The conceptual framework constructed suggests several alternative courses of action Flex-Mex could pursue to remedy this mismatch. First, it could extend the application of its IT to more completely circumscribe the tasks of its employees. This could include timing an order from when it is placed with the order taker to when it is placed on the customer pick-up portion of the front counter and not electronically permit back room employees to "bump" orders from their screens. The IT system could also be reengineered to account for redoing misfilled orders. Such changes in IT's application would certainly restrict the extent to which employees could make perverse judgments. It would also, however, undoubtedly further intensify the hostility of the work environment and could lead to other undesirable results. Flex-Mex could also consider empowering its employees in ways that could possibly even dispense with any need to reengineer its IT system. Revising the incentive and performance measurement systems would be a start. Tying their rewards to the success of both their local operation and the organization at large might do better at gaining the loyalty and dedication of Flex-Mex's customer service personnel than providing them half-price menu items (McNerney, 1996). This would be especially so if these personnel had some say as to what those rewards would be and how their performance should be measured. This does not necessarily mean that the use of judgment and the exercise of discretion in doing their jobs would be increased. These jobs require the use and exercise of little judgment and discretion. Rather, it would mean that Flex-Mex's customer contact service personnel had a stake in how well Flex-Mex does. 


\section{Conclusion}

This paper has provided a conceptual framework for exploring the dynamics that arise in managing the integration of operations, technology (primarily IT), and human resources. It has focused on how mismatched combinations of operations, technology, and human resources impact the use and exercise of judgment and discretion by customer contact service personnel and how these organizational anomalies can be eliminated.

The few examples presented in this paper hardly provide sufficient data to empirically validate this framework and the kinds of organizational mismatches it identifies. Furthermore, the off-diagonal categories have not been addressed. Therefore, further work empirically validating and perfecting this framework or developing one to more accurately categorize types of service organizations in order to better isolate types of intra-organizational mismatches is in order. Beyond that is the issue of determining from among a set of alternative courses of action the framework specifies which alternative is the most appropriate to pursue in eliminating organizational mismatches. Thus, it will be necessary to identify, select, and develop measures as well as techniques to process these measures to rigorously determine the appropriate alternative course of action. The authors believe that this program of applied research is both fruitful and valuable inasmuch as it addresses potential service operations ineffectiveness and inefficiency resulting from failures integrating technology and human resources and could contribute to sorting out the factors that have resulted in the "information technology paradox."

\section{References}

Bowen, D., \& Lawler III, E. (1992). The empowerment of service workers: What, why, how, and when. Sloan Management Review, Spring, 31-39.

Clark, C. The conditions of economic progress 3rd ed. London: The Macmillan Co.

Cook, D.P., Gho, C.H., \& Chung, C.H. (1988). Service typologies: A state of the art survey. Production and Operations Management. 8, 318-338.

Committee to Study the Impact of Information Technology on the Performance of Service Activities. (1994). Information Technology in the Service Society. Washington, DC: National Academy Press.

Dunkin, A. (1999). All the world's an auction. Business Week, Feb. 8, 1999, 120-121.

Dwyer, S.B., Sayre, S.J., \& Honeyman, J. (1992). Wide area network strategies for teleradiology systems. Radiographics, 12 (30), 567-576. 
Festa, F. (1987). Methodology to evaluate CAD/CAE/CAM systems. Computer Applications in Production and Engineering, 893-912.

Fitzsimmons, J. (1993). Strategic role of information in services. Perspectives in operations management: Essays in honor of Elwood S. Buffa. R. Sarin (ed.). Norwell, MA: Kluwer Academic.

Fitzsimmons, J., \& Fitzsimmons, M. (1997). Service management: Operations, strategy and information technology 2nd ed. Boston: Irwin/McGraw-Hill,

Franken, E. (1998). Teleradiology: Moving into the mainstream. Telemedicine Today, 4 (1), 6-7.

Gerwin, D., \& Kolodny, H. (1992). Management of advanced manufacturing technology: Strategy, organization. and innovation. New York: John Wiley and Sons, Inc.

Hartline, M.D., \& Ferrell, O.C. (1996). The management of customer contact service employees: An empirical investigation. Journal of Marketing. 60, 52-71.

Hauser, J.R., \& Clausing, D., (1988). The house of quality. Harvard Business Review, May-June, 63-73.

Heitoff, K. (1998). Reinventing the wheel. Decisions in Imaging Economics. 11 (2), 1216.

Kellogg, D.L., \& Nie, W. (1995). A framework for strategic service management. Journal of Operations Management. 13, 323-337.

Keltner, B., \& Finegold, D. (1999). Market segmentation strategies and service sector productivity. California Management Review, 41 (4), 84-103.

Kerr, S. (1995). On the folly of rewarding A, while hoping for B. Academy of Management Executive 9 (1), 7-16.

Lovelock, C. (1993). Classifying services to gain strategic marketing insights. Journal of Marketing. 47, 9-20.

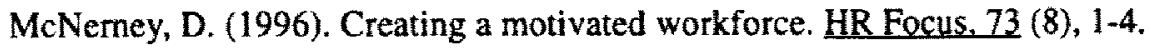

Mechling, G., \& Little, B. (1997). Operations and HRM: Can IT merge the two in support of business strategy. Journal of the International Academy for Case Studies. 3 (1), 811.

Meredith, J. (1986). Automation strategy must give careful attention to the firm infrastructure. Industrial Engineering. 18 (5), 783-792. 
Mills, P., \& Moberg, D. (1982). Perspectives on the technology of service operations. Academy of Management Review, 7, 467-478.

Riddle, D. (1986). Service-led growth. New York: Praeger.

Rodger, J., \& Paper, D. (1998). An empirical study for measuring operating room quality performance attributes. Journal of High Technology Management Research. 9 (1), 131-157.

Schmenner, R. (1986). How can service businesses survive and prosper? Sloan Management Review. Spring, 21-32.

Sciulli, L. (1998). How organizational structure influences success in various types of innovation. Journal of Retail Banking Services, 20 (1), 13-19.

Singh, S., \& Deshmukh, S.G. (1999). Quality initiatives in the service sector: A case. Total Quality Management. 10, 5-18.

1 This empirical observation, the Clark-Fisher hypothesis, explains employment shifts toward sectors of lower productivity (Clark, 1957).

${ }^{2}$ According to Cook, Gho, and Chung (1988), researchers have developed different typologies to answer specific questions - a pragmatic consideration. Therefore, the authors believe that they have sufficient warrant to employ one of Lovelock's typologies because of its implicit usefulness to the question at hand.

${ }^{3} \mathrm{~A}$ competitive advantage can be achieved by providing a low-cost speedy standardized service to a large market segment with similar needs or by providing customized service to a segment whose needs are dissimilar. In the first case customizing services would be inefficient, strategically contradictory, and possibly annoy customers delayed by the preferential treatment they perceive others receiving. In the latter case, such customization would be strategically necessary because it would be what was expected.

4 A totally circumscribed job design is one in which every organizationally sanctioned course of action customer encounter personnel can take as a part of their job is executed through the IT system.

5 The extent to which a particular service is technologically circumscribed, if at all, depends of course on factors other than the mere fact that it can be done. Certainly the benefits gained and the costs incurred to so circumscribe a set of tasks are major onsiderations. 
${ }^{6}$ From conversations with Delta, USAir, and TWA airport ticket/check-in counter personnel.

George W. Mechling is an Associate Professor in Management at Western Carolina University. Dr. Mechling's teaching and research interests include operations management, operations management, and the management of technology and innovation.

Beverly Little is an Associate Professor in Management at Western Carolina University. Dr. Little's teaching and research interests include human resource management and organizational behavior. 